\title{
COMBUSTION AND PYROLYSIS CHARACTERISTICS OF TUNÇBİLEK LIGNITE
}

\author{
I. Y. Elbeyli ${ }^{*}$ and S. Pişkin \\ Department of Chemical Engineering, Y1ldız Technical University, 34210 İstanbul, Turkey
}

In this study, thermal characteristics and kinetic parameters of cleaned Tunçbilek lignite were determined by using a Setaram Labsys DTA/TG/DSC thermal analysis system both for combustion and pyrolysis reactions. Experiments were performed at a heating rate of $10^{\circ} \mathrm{C} \mathrm{min}^{-1}$ under reactive (air) and inert (nitrogen) gases up to $1000^{\circ} \mathrm{C}$. Non-isothermal heating conditions were applied and reaction intervals were determined for combustion and pyrolysis reactions from obtained curves. The combustion properties were evaluation by considering the burning profile of the lignite sample. Burning temperatures and rate of combustion were determined from TG/DTG curves. Calorific value of the lignite sample was measured by DSC curve and compared with the adiabatic bomb calorimeter result.

In addition to investigation of the combustion properties, pyrolysis characteristics of the lignite sample were investigated based on TG/DTG/DSC curves. Activation energy $(E)$ and pre-exponential factor $(A)$ were calculated from the TG data by using a Coats-Redfern kinetic model both for combustion and pyrolysis reactions of cleaned Tunçbilek lignite.

Keywords: combustion, kinetics, lignite, pyrolysis, thermal analysis

\section{Introduction}

Thermogravimetric analyses (TG) together with DTA or DSC are effective methods commonly used for quantitative determination of mass loss as a function of the gradual increase in temperature [1]. The methods play an important role in the investigation of thermal characteristics of mineral matters. Various methods such as thermogravimetric analysis (TG), differential thermal analysis (DTA), dynamic microcalorimetric analysis (DMA) and swelling index (SI) measurements have been developed to determine the thermal characteristics of coals. Thermal characteristics of coal change depend mainly on its chemical constituents, macerals, rank, grade, origin, etc. [2, 3].

Coal undergoes a series of complex physical and chemical changes during the combustion and pyrolysis. Combustion characteristics such as heat content, ignition and burn off temperatures and maximum rate of mass loss are of important in coal utilization and these features can be determined from the TG and DTG curves of the coal samples [4,5]. Also, pyrolysis of coal is of important for beneficiation from coal due to being the first step in coal conversion processes like carbonization, liquefaction, combustion and gasification [6].

Previous studies on DTA/TG/DSC analysis of lignite and bituminous coals carried out under different experimental conditions. Results show that the thermal behaviour of coals depends on experimental conditions such as particle size, sample amount, heating rate and gas flow rate. Pişkin et al. [7] investigated the thermal reactivities of five Turkish lignites (Elbistan, Ilgın, Karlıova, Kangal and Yatağan) under air atmosphere and show the correlations between heat contents measured by DTA and calorific values of the coal samples measured by adiabatic bomb calorimeter. Kök et al. [8] investigated that combustion characteristics of lignite and oil shale samples by thermal analysis techniques and kinetic calculations performed for oxidation. Iordanidis et al. [1] investigated combustion properties and burning profiles of Greece lignites and they showed good correlations between results of proximate and calorimetry analyses and DTA/TG data. Arenillas et al. [9] determined by using the TG/DTA techniques that effects of coal blending on combustion characteristics. Kök et al. [10] determined that thermogravimetric characterization of ten lignites and kinetic calculation for their oxidation processes. Kök [11] carried out coal combustion experiments in air atmosphere up to $600^{\circ} \mathrm{C}$ at a heating rate of $10^{\circ} \mathrm{C} \mathrm{min}^{-1}$ by using DSC and calculated the kinetic parameters beneficiation from Arrhenius and Coats-Redfern plots.

In addition to combustion studies of coal by using TG/DTA/DSC, investigations of pyrolysis properties of bituminous coal and lignites have been studied by many investigators. Elder and Harris [12] investigated the thermal characteristics of Kentucky bituminous coals

Author for correspondence: ielbeyli@yildiz.edu.tr 
during pyrolysis in an inert atmosphere. They determined the exothermic reaction at a range of 300 to $500^{\circ} \mathrm{C}$, where the major mass loss occurs and which has been associated with the primary carbonisation process and the development of a plastic state. Elbeyli et al. [13] investigated pyrolysis stages and kinetics parameters of some Turkish bituminous coals in nitrogen atmosphere up to $1000^{\circ} \mathrm{C}$ under non-isothermal condition by using TG/DTG methods. Sinağ [14] investigated the kinetics of Soma lignite in water vapor and inert atmosphere (nitrogen) and the effects of pyrolysis condition on the reactivity of Soma lignite.

The aim of the present study is to investigate the thermal behaviour and kinetics of cleaned Tunçbilek lignite at non-isothermal heating conditions both for combustion and pyrolysis reaction by TG/DTG and DSC techniques.

\section{Experimental}

\section{Sample preparation}

Lignite was supplied from the Tunçbilek in Kütahya as cleaned sample and prepared according to the ASTM Standards (ASTM D 2013-04). The sample was sieved to pass $250 \mu \mathrm{m}$ sieve and then ultimate and proximate analyses were performed according to the ASTM Standards (ASTM D 3174-04, D 3175-02, D 3176-89). A high-temperature furnace, a LecoCHN 600 element analyzer and a Leco-S132 sulfur analyzer were used in proximate and ultimate analyses. Calorific value of the sample determined by using an adiabatic bomb calorimeter (IKA-Calorimeter C4000 adiabatic) which had been calibrated using benzoic acid according to the ASTM Standards (ASTM D 5865-04). Results are present in Table 1.

\section{Determination of functional groups and microstructure of lignite sample}

Functional groups of the cleaned Tunçbilek lignite sample were determined by PerkinElmer Spectrum One model FTIR instrument. The pellet was prepared by

Table 1 Proximate and ultimate analyses of Tunçbilek lignite

\begin{tabular}{|c|c|}
\hline Proximate analysis & $\operatorname{Mass} \%{ }^{\mathrm{a}}$ \\
\hline Moisture & 10 \\
\hline Ash & 16 \\
\hline Volatile matter & 34 \\
\hline Fixed carbon & 50 \\
\hline Ultimate analysis & \\
\hline $\mathrm{C}$ & 61.24 \\
\hline $\mathrm{H}$ & 4.52 \\
\hline $\mathrm{N}$ & 2.69 \\
\hline S & 1.91 \\
\hline $\mathrm{O}$ (difference) & 29.64 \\
\hline
\end{tabular}

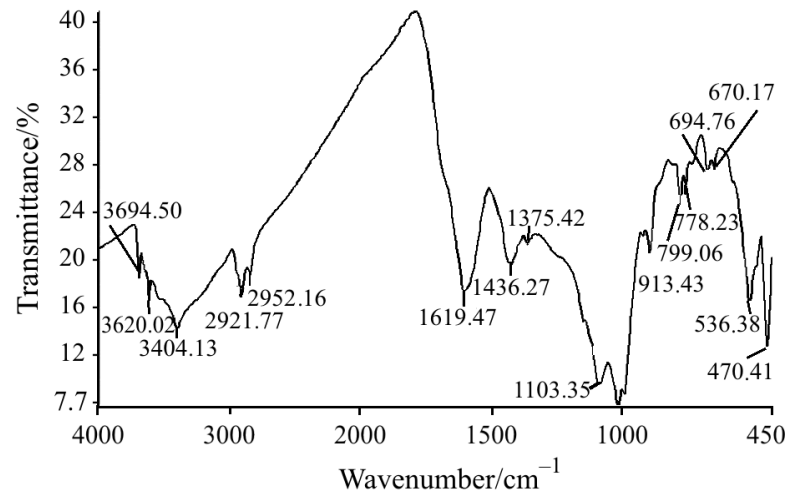

Fig. 1 FTIR spectrum of Tunçbilek lignite

mixing $1 \mathrm{mg}$ of dried lignite sample and $100 \mathrm{mg}$ of $\mathrm{KBr}$. Then the mixture was pressed under $10 \mathrm{~kg} \mathrm{~cm}^{-2}$ pressure and then dried in a vacuum furnace. The FTIR spectra was recorded in the region of 4000 to $400 \mathrm{~cm}^{-1}$ (Fig. 1). The peak assignments in this paper are based on the work (Table 2) [16]. Surface microstructures of the sample was obtained using JEOL JSM-5410 model scanning electron microscope (SEM) (Fig. 2).

\section{Thermal experiments}

Setaram Labsys TG/DTA/DSC model thermal analysis system was used in experiments. TG apparatus was calibrated via the melting points of indium $\left(T_{\mathrm{m}}: 156.6^{\circ} \mathrm{C}\right)$, tin $\left(T_{\mathrm{m}}: 231.9^{\circ} \mathrm{C}\right)$, lead $\left(T_{\mathrm{m}}: 327.5^{\circ} \mathrm{C}\right)$, zinc $\left(T_{\mathrm{m}}: 419.6^{\circ} \mathrm{C}\right)$, aluminum $\left(T_{\mathrm{m}}: 660.2^{\circ} \mathrm{C}\right)$ and gold

Table 2 Band assignments in FTIR spectra of coal [16]

\begin{tabular}{ll}
\hline Bands $/ \mathrm{cm}^{-1}$ & Assignments \\
\hline $3420-3320$ & - OH stretching \\
$3050-3030$ & Aromatic $\mathrm{CH}$ stretching \\
$3000-2800$ & Aliphatic $\mathrm{CH}$ stretching \\
1700 & $\begin{array}{l}\text { Aromatic carbonyl/carboxyl } \mathrm{C}=\mathrm{O} \\
\text { stretching }\end{array}$ \\
$1610-1560$ & Aromatic $\mathrm{C}=\mathrm{C}$ ring stretching \\
1510 & Aromatic $\mathrm{C}=\mathrm{C}$ ring stretching \\
1450 & Aliphatic $\mathrm{CH}$ deformation \\
$1430-1420$ & Aromatic $\mathrm{C}=\mathrm{C}$ ring stretching \\
$1370-1360$ & Aliphatic $\mathrm{CH}$ deformation \\
$1317-1315$ & Aliphatic $\mathrm{CH}_{2}$ deformation \\
$1270-1250$ & $\begin{array}{l}\text { Aromatic } \mathrm{CO}-\text { and phenolic }-\mathrm{OH} \\
\text { stretching }\end{array}$ \\
$1060-1030$ & Aliphatic ether C-O-and alcohol \\
870 & C-O stretching \\
810 & 1 adjacent $\mathrm{H}$ deformation \\
$780-770$ & 2 adjacent $\mathrm{H}$ deformation \\
750 & Aliphatic $\mathrm{CH}_{2}$ deformation \\
& 3-4 adjacent $\mathrm{H}$ deformation \\
\hline
\end{tabular}



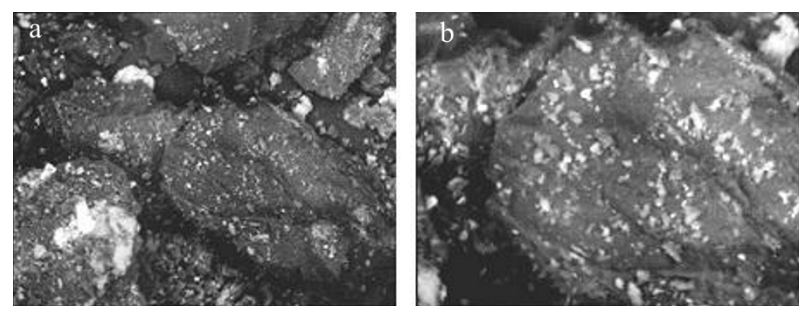

Fig. 2 SEM micrographs of Tunçbilek lignite in $\mathrm{a}-500 \times$ and $\mathrm{b}-1000 \times$

$\left(T_{\mathrm{m}}: 1063^{\circ} \mathrm{C}\right)$ metals under the same conditions as for the sample. During the experiments, the mass loss (TG signal) and the rate of mass loss (DTG signal) as a function of time or temperature were recorded, while the lignite was subjected to a computer-controlled temperature programme.

Combustion experiments were carried out by using TG/DSC rode under air atmosphere flow rate of $100 \mathrm{~mL} \mathrm{~min}{ }^{-1}$ up to $1000^{\circ} \mathrm{C}$. The experiments carried out with the powdered sample with a size of approximately $10 \mathrm{mg}$ and with a heating rate of $10^{\circ} \mathrm{C} \mathrm{min}^{-1}$.

The characteristic temperatures of the combustion process were determined from the DTG curves. It is known that these temperatures use to define significant events during the combustion of a coal [15]. At the second stage of the experimental procedure, pyrolysis was investigated under pure inert gas $\left(\mathrm{N}_{2}\right.$, $99.9 \%$ ) with a heating rate of $10^{\circ} \mathrm{C} \mathrm{min}^{-1}$ up to $1000^{\circ} \mathrm{C}$. Pyrolysis stages and characteristics temperatures were determined from TG/DTG curves.

\section{Kinetic theory}

TG/DTG technique is useful techniques for the determination of decomposition temperatures and decomposition steps for solid substance. A number of models have been developed to obtain the kinetic parameters from the thermogravimetric data for studying the mechanism of solid-state decomposition processes. The mathematical procedure used in the present study, in the analysis of TG data for determining the decomposition kinetics, is based on the Coats-Redfern method used by many other investigators [17-19]. Aybers [19] show that equations of the method as follow,

$$
a A_{(\mathrm{s})} \rightarrow b B_{(\mathrm{s})}+c C_{(\mathrm{g})}
$$

the rate of disappearance of $A$ may be expressed by

$$
\frac{\mathrm{d} \alpha}{\mathrm{d} t}=k(1-\alpha)^{\mathrm{n}}
$$

where $\alpha$ is the fraction of $A$ decomposed at time $t, n$ is the order of reaction and $k$ is the rate constant given by the expression

$$
k=A \mathrm{e}^{-\mathrm{E} / \mathrm{RT}}
$$

where $A$ is the frequency factor or pre-exponential factor and $E$ is the activation energy of the reaction. $A$ is considered for gases and liquids as frequency factor and is proportional to the number of successful collisions of the reaction molecules. Solid particles are not free to move and $A$ can be considered as a pre-exponential constant. For linear heating rate of, say a ${ }^{\circ} \mathrm{C} \mathrm{min}^{-1}$,

$$
\alpha=\frac{\mathrm{d} T}{\mathrm{~d} t}
$$

Combining Eqs (2)-(4), rearranging and integrating,

$$
\int_{0}^{\alpha} \frac{\mathrm{d} \alpha}{(1-\alpha)^{\mathrm{n}}}=\frac{A}{\alpha} \int_{0}^{\mathrm{T}} \mathrm{e}^{-\mathrm{E} /(\mathrm{RT})} \mathrm{d} T
$$

The right-hand side of Eq. (5) has no exact integral, but by making the substitutions $u=E /(R T)$ and using the relation

$$
\int_{\mathrm{u}}^{\infty} \mathrm{e}^{-\mathrm{u}} u^{-\mathrm{b}} \mathrm{d} u \cong u^{1-\mathrm{b}} \mathrm{e}^{-\mathrm{u}} \sum_{\mathrm{n}=0}^{\infty} \frac{(-1)^{\mathrm{n}}(b)^{\mathrm{n}}}{u^{\mathrm{n}+1}}
$$

Equation (5) becomes

$$
\frac{1-(1-\alpha)^{1-\mathrm{n}}}{1-n}=\frac{A R T^{2}}{a E}\left[1-\frac{2 R T}{E}\right] \mathrm{e}^{-\mathrm{E} / \mathrm{RT}}
$$

taking $\ln s$

$$
\ln \left[\frac{1-(1-\alpha)^{1-\mathrm{n}}}{T^{2}(1-n)}\right]=\ln \frac{A R}{a E}\left[1-\frac{2 R T}{E}\right]-\frac{E}{R T}
$$

for all values of $n$ except $n=1$ in which case Eq. (5). After taking $\ln s$, becomes

$$
\ln \left[-\ln \frac{(1-\alpha)}{T^{2}}\right]=\ln \frac{A R}{a E}\left[1-\frac{2 R T}{E}\right]-\frac{E}{R T}
$$

Thus a plot of either

$$
\ln \left[\frac{1-(1-\alpha)^{1-\mathrm{n}}}{T^{2}(1-n)}\right] \text { vs. } \frac{1}{T}
$$

or, where $n=1$,

$$
\ln \left[\frac{-\ln (1-\alpha)}{T^{2}}\right] \text { vs. } \frac{1}{T}
$$

should result in a straight line of slope $-E /(R T)$ for the correct value of $n$, since it may be shown that, for most values of $E$ and for the temperature range over which reactions generally occur, the expression

$$
\ln \frac{A R}{a E}\left[1-\frac{2 R T}{E}\right]
$$

is sensibly constant. In that case, Eqs (8) and (9) can be written as $y=a x+b$ : 


$$
b=\ln \frac{A R}{a E}\left[1-\frac{2 R T}{E}\right] ; x=\frac{1}{T}, a=-\frac{E}{R}
$$

where $E$ and $A$ can be calculated from the slope and the intercept.

By using the $\alpha$ values, a plot of left side of Eqs (8) or (9) vs. 1/T should give straight lines for a correct value of $n$. In the evaluation of Eq. (8), the best value for $n$ was searched in the range from 0.2 to 2.5 to get a straight line. The $n$ value giving a straight line with a highest correlation coefficient was assumed to be the order of the overall pyrolysis and combustion reactions [20]. The main temperature range of volatile evolution $\left(350-600^{\circ} \mathrm{C}\right)$ was always taken into account in the calculation and a regression factor, $R^{2}$, was obtained in both processes $[8,9,13]$.

\section{Results and discussion}

\section{Chemical structure of the lignite sample}

The FTIR spectrum of the lignite sample is given in Fig. 1. The absorptions at 3694 and $3620 \mathrm{~cm}^{-1}$ are due to intermolecular and weakly $\mathrm{H}$ bonded $\mathrm{OH}$ because of water of crystallization in clay minerals [21]. The broad band at $3401 \mathrm{~cm}^{-1}$ show the hydroxyl groups in water or phenolic compounds. Bands around at 2921 and $2852 \mathrm{~cm}^{-1}$ show the symmetric and asymmetric stretching vibration of $\mathrm{C}-\mathrm{H}$ due to the presence of aliphatic hydrocarbon species. The bands at $1619 \mathrm{~cm}^{-1}$ can be assigned to the aromatic $\mathrm{C}=\mathrm{C}$ ring stretching vibrations. Other absorption bands in FTIR spectra of the lignite were at $1436 \mathrm{~cm}^{-1}$ (aromatic $\mathrm{C}=\mathrm{C}$ ring stretching band), $1375 \mathrm{~cm}^{-1}$ (aliphatic $\mathrm{CH}_{3}$ deformation band), $1000-1200 \mathrm{~cm}^{-1}$ (aliphatic ether $\mathrm{C}-\mathrm{O}$ and alcohol $\mathrm{C}-\mathrm{O}$ stretching bands), 778-799 $\mathrm{cm}^{-1}$ (aliphatic $\mathrm{C}-\mathrm{H}$ stretching bands) and $690-470 \mathrm{~cm}^{-1}$ (mineral matters such as calcium sulfate, pyrite, etc.).

As it can be seen in Fig. 2 lignite has more heterogeneous structure due to different mineral contents such as quartz, kaolinite and calcite.

\section{Combustion characteristics of the lignite sample}

The thermal parameters (e.g. characteristic temperatures and maximum rate of mass loss) were derived from combustion profile by TG/DTG $[8,15]$. The TG/DTG curve obtained from the combustion under air atmosphere of Tunçbilek lignite is presented in Fig. 3 . The TG curve indicates two mass loss regions, dehydration and combustion occurs in two steps. The first one is observed in the range from 35 to $150^{\circ} \mathrm{C}$, with a DTG peak at $56^{\circ} \mathrm{C}$ that corresponds to the loss of $5.3 \%$. This loss corresponds to the elimination of the hydrated water, small amount of pyrolysis water from decomposing phenolic groups [23]. The essential mass

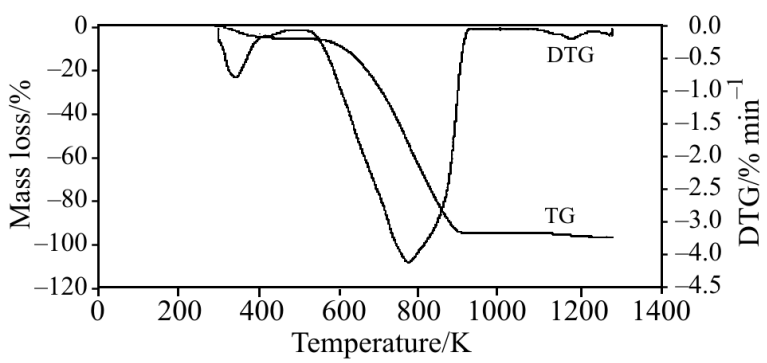

Fig. 3 TG/DTG curve of Tunçbilek lignite for combustion under reactive gas (air)

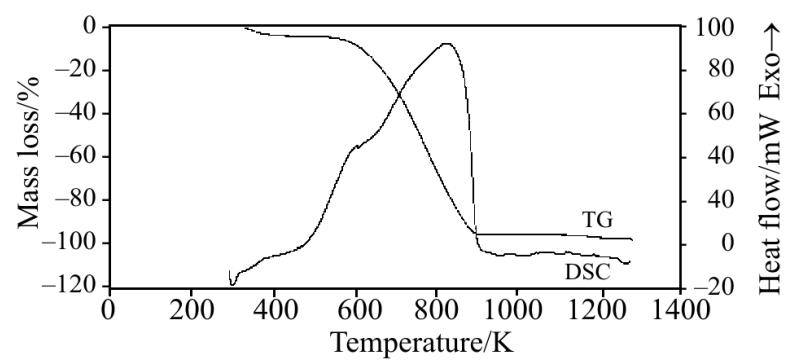

Fig. 4 TG/DSC curve of Tunçbilek lignite for combustion under reactive gas (air)

loss due to combustion observed in the range from 310 to $655^{\circ} \mathrm{C}$, with a DTG peak at $500^{\circ} \mathrm{C}$ that corresponds to the loss $88.8 \%$. At around $300^{\circ} \mathrm{C}$ primary reaction starts initially with the carbon dioxide and also methane and other aliphatics evolves together with hydrogen, carbon monoxide and alkyl aromatics with increasing temperature [11]. The maximum rate of combustion was confirmed as $4 \% \mathrm{~min}^{-1}$ from the DTG peak. DSC curve of the lignite sample is shown in Fig. 4. It can be seen from the DSC curve that major reaction related to the combustion occurs in the range from 300 to $650^{\circ} \mathrm{C}$, with a peak at $558^{\circ} \mathrm{C}$. At this stage, heat of reaction is calculated as $21.90 \mathrm{~kJ} \mathrm{~kg}^{-1}$ from the DSC peak area. The expected thermal effect in region is therefore exothermic. In this region, lignite conducted in oxygen, the reactions taking place can effectively be viewed as combustion reactions. The amount of heat released largely depends on the strength of the bonds broken in the lignite structure to form the products, i.e. $\mathrm{CO}, \mathrm{CO}_{2}, \mathrm{H}_{2} \mathrm{O}, \mathrm{N}_{\mathrm{x}} \mathrm{O}, \mathrm{N}_{2} \mathrm{O}, \mathrm{SO}_{2}, \mathrm{SO}_{3}$ [18]. In addition to the DSC result, calorific value was measured by the adiabatic bomb calorimeter method as $24.03 \mathrm{~kJ} \mathrm{~kg}^{-1}$. It was noted that the bomb calorimeter value is the higher heating values including the latent heat of $\mathrm{H}_{2} \mathrm{O}$ formed upon combustion of coal hydrogen [7].

\section{Pyrolysis characteristics of the lignite sample}

TG/DTG and TG/DSC curves of Tunçbilek lignite for pyrolysis under nitrogen atmosphere are given in Figs 5 and 6 , respectively. According to the TG curve, based on two mass loss regions, dehydration and pyrolysis occurs in two steps. The first one is observed in the range 


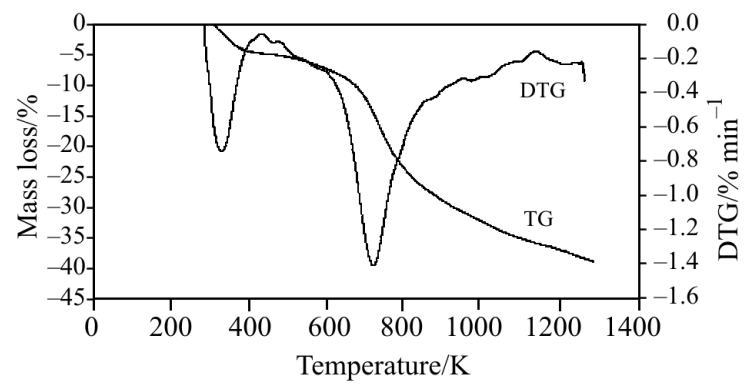

Fig. 5 TG/DTG curve of Tunçbilek lignite for pyrolysis under inert gas (nitrogen)

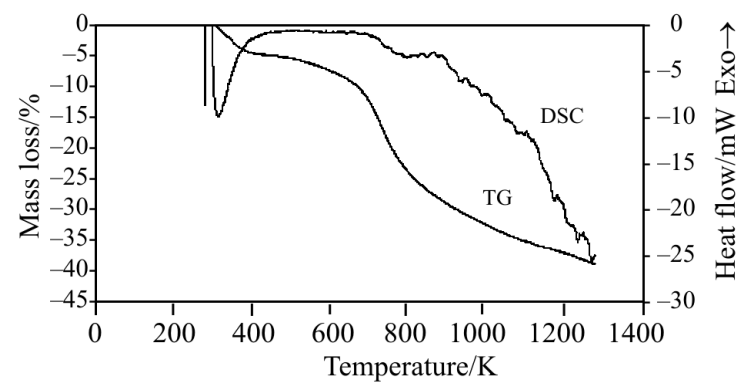

Fig. 6 TG/DSC curve of Tunçbilek lignite for pyrolysis under inert gas (nitrogen)

from 35 to $160^{\circ} \mathrm{C}$, with a DTG peak at $85^{\circ} \mathrm{C}$ that corresponds to the loss of $4.8 \%$. This loss corresponds to the elimination of the hydrated water. A second mass loss is observed in the range from 300 to $600^{\circ} \mathrm{C}$, with a DTG peak at $458^{\circ} \mathrm{C}$ that corresponds to the loss $27.4 \%$. The essential mass loss in pyrolysis occurs mainly in $350-650^{\circ} \mathrm{C}$ region in accordance to the DTG profile. On the TG curve, it is noticed that initial temperature of the pyrolysis reaction at $390^{\circ} \mathrm{C}$ and the reaction is continuous at $500^{\circ} \mathrm{C}$ as fastly. According to the literature, temperature regions in pyrolysis explain as follows: Temperature below $350-400^{\circ} \mathrm{C}$, where different process takes place prior to primary pyrolysis, i.e., disruption of hydrogen bonds, vaporisation and transport of the non-covalently bonded molecular phase. The primary pyrolysis takes place between at $350-600^{\circ} \mathrm{C}$ and the stage is shown as strongest pyrolysis in TG curve. This consists of a primary degradation, as a result of which the weakest bridges may break to produce molecular fragments. The fragments abstract hydrogen from the hydroaromatics or aliphatics, thus increasing the concentration of aromatic hydrogen. These fragments will be released as tar if they are small enough to vaporize and be transported out of the char particle [22]. Functional groups also decompose to release gases, mainly $\mathrm{CO}_{2}$, light aliphatics, $\mathrm{CH}_{4}$ and $\mathrm{H}_{2} \mathrm{O}$. The maximum rate of the pyrolysis was determined as $1.4 \% \mathrm{~min}^{-1}$ from the DTG curve and the DSC curve do not show the any significant changes during the pyrolysis except for endothermic peak arised from the moisture.

\section{Kinetic analysis results}

Decomposing fraction $(\alpha)$ at any time in combustion was determined based on TG curve and used in calculation of kinetic parameters (Fig. 3). Kinetic calculations for pyrolysis were evaluated for strongest stage in pyrolysis. The main temperature range of volatile evolution $\left(400-550^{\circ} \mathrm{C}\right)$ was always taken into account in the calculations, and a correlation coefficient $\left(R^{2}\right)$ was obtained.

The non-isothermal kinetic study of mass loss during combustion and pyrolysis were performed by using TG data. The calculation of kinetic data is based on Coats-Redfern method [17]. In the calculation, Eq. (8), the best value for $n$ was searched by a computer programme in the range from 0.2 to 2.5 to get a straight line. The $n$ value giving a straight line with a highest correlation coefficient was assumed to be the order of the decomposing stage. The values of $E$ and $A$ were then calculated from the slope and the intercept of the line, respectively. Regression analysis was employed in the estimation of $n, E$ and $A$ for pyrolysis and combustion. The plots of $n^{\text {th }}$ order rate model for the second endotherm in DSC curves both for combustion and pyrolysis are given in Figs 7 and 8 . The results indicated that $n=0.7$ and $n=2.5$ value for combustion and pyrolysis reactions, respectively, gives straight lines with high correlation coefficients.

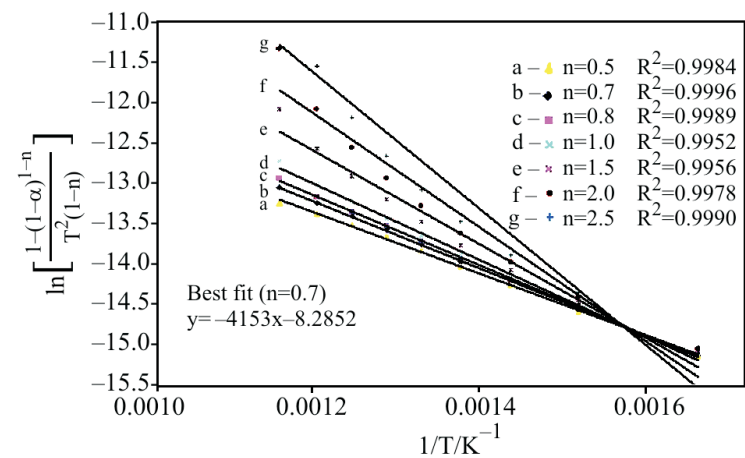

Fig. 7 Determination of the kinetic parameters by using TG data for the combustion

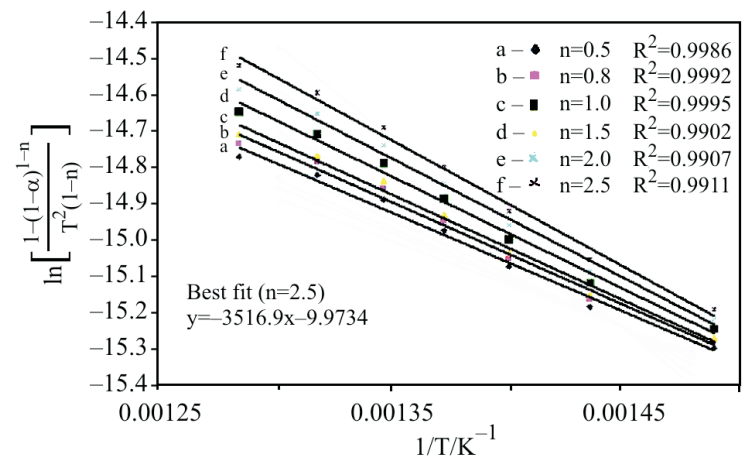

Fig. 8 Determination of the kinetic parameters by using TG data for the pyrolysis 


\section{Conclusions}

In this research, thermal characteristics of cleaned Tunçbilek lignite during the combustion and pyrolysis were determined by TG/DTG/DSC thermal analysis methods and kinetic analysis of thermogravimetry (TG) data was carried out by using Coats-Redfern kinetic model at non-isothermal conditions.

- Two mass loss was observed in TG both for combustion and pyrolysis, dehydration and main reaction region.

- DSC and adiabatic bomb calorimeter method show the parallel results in view of calorific values.

- The results indicated that activation energy values of combustion and pyrolysis reactions are 34.53 and $29.24 \mathrm{~kJ} \mathrm{~mol}^{-1}$, respectively. Pre-exponential factors for the reactions calculated based on the Coats-Redfern method are 10.47 and $1.64 \mathrm{~min}^{-1}$, respectively.

\section{References}

1 A. Iordanidis, A. Georgakopoulos, K. Markova, A. Filipiddis and A. Kassoli-Fournaraki, Thermochim. Acta, 371 (2001) 137.

2 O. Kural, Characteristics, Technology and Environmental Relations of Coal, İstanbul Technical University, (1998) 113.

3 M. V. Kök, J. Therm. Anal. Cal., 68 (2002) 1061.

4 M. V. Kök and C. Keksin, J. Therm. Anal. Cal., 64 (2001) 1265.

5 M. V. Kök, J. Therm. Anal. Cal., 64 (2001) 1319.

6 L. Yongkank, C. Liping and X. Kechang, Energy Sources, 23 (2001) 717.

7 S. Pişkin, S. Ünal, A. Kuyulu and S. Dinçer, Fuel Sci. Technol., 10 (1992) 243.
8 M. V. Kök, G. Pokol, C. Keskin, J. Madarász and S. Bagci, J. Therm. Anal. Cal., 76 (2004) 247.

9 A. Arenillas, F. Rubiera, B. Arias, J. J. Pis, J. M. Faúndez, A. L. Gordon and X. A. Garcia, J. Therm. Anal. Cal., 76 (2004) 603.

10 M. V. Kök, G. Pokol, C. Keskin, J. Madarász and S. Bagci, J. Therm. Anal. Cal., 75 (2004) 781.

11 M. V. Kök, J. Therm. Anal. Cal., 79 (2005) 175.

12 J. P. Elder and M. B. Harris, Fuel, 63 (1984) 262.

13 I. Y. Elbeyli, S. Pişkin and H. Sütcü, Turk. J. Eng. Env. Sci., 28 (2004) 233.

14 A. Sinağ, Energy Sources, 26 (2004) 127.

15 S. Kizgut, D. Çuhadaroğlu and I. Toroğlu, Turkish J. Chem., 27 (2003) 521.

16 P. C. Peinter, M. Starsinic and M. M. Coleman, Determination of Functional Groups in Coal by Fourier Transform Interferometry, Fourier Transform Infrared Spectroscopy, Academic Press, New York, 4 (1985) 169.

17 A. W. Coats and J. P. Redfern, Nature, 201 (1964) 68.

18 M. V. Kök and C. Keskin, J. Thermal Anal., 49 (1997) 617.

19 M. T. Aybers, J. Nucl. Mater., 252 (1998) 28.

20 K. Ceylan, H. Karaca and Y. Önal, Fuel, 78 (1999) 1109.

21 V. S. Joshi and M. J. Joshi, Cryst. Res.Technology, 38 (2003) 817.

22 A. Arenillas, F. Rubiera, C. Pevida and J. J. Pis, J. Anal. Appl. Pyrolysis, 58 (2001) 685.

23 K. E. Ozbas, M. V. Kök and C. Hicyilmaz, J. Therm. Anal. Cal., 71 (2003) 849.

Received: February 4, 2005

Accepted: August 10, 2005

OnlineFirst: December 12, 2005

DOI: $10.1007 / \mathrm{s} 10973-005-6830-5$ 